\title{
Removing Brakes on Adult Brain Plasticity: From Molecular to Behavioral Interventions
}

\author{
Daphne Bavelier, ${ }^{1}$ Dennis M. Levi, ${ }^{2}$ Roger W. Li, ${ }^{2}$ Yang Dan, ${ }^{3}$ and Takao K. Hensch ${ }^{4,5}$ \\ ${ }^{1}$ Department of Brain and Cognitive Sciences, University of Rochester, Rochester New York 14627-0268, ${ }^{2}$ School of Optometry and Helen Wills \\ Neuroscience Institute, and ${ }^{3}$ Department of Molecular and Cell Biology, Howard Hughes Medical Institute, University of California, Berkeley, California \\ 94720, ${ }^{4}$ Center for Brain Science, Department Molecular Cellular Biology, Harvard University, Cambridge, Massachusetts 02138, and ${ }^{5}$ Department of \\ Neurology, F. M. Kirby Neurobiology Center, Children's Hospital Boston, Harvard Medical School, Boston, Massachusetts 02115
}

Adult brain plasticity, although possible, remains more restricted in scope than during development. Here, we address conditions under which circuit rewiring may be facilitated in the mature brain. At a cellular and molecular level, adult plasticity is actively limited. Some of these "brakes" are structural, such as perineuronal nets or myelin, which inhibit neurite outgrowth. Others are functional, acting directly upon excitatory-inhibitory balance within local circuits. Plasticity in adulthood can be induced either by lifting these brakes through invasive interventions or by exploiting endogenous permissive factors, such as neuromodulators. Using the amblyopic visual system as a model, we discuss genetic, pharmacological, and environmental removal of brakes to enable recovery of vision in adult rodents. Although these mechanisms remain largely uncharted in the human, we consider how they may provide a biological foundation for the remarkable increase in plasticity after action video game play by amblyopic subjects.

\section{Introduction}

Neural circuits are shaped by genes and environment during early windows of brain development. Since the classic work of Hubel and Wiesel (1970) on visually deprived cats, most cortical systems are thought to be molded by experience during a "sensitive period" in early life. Considerable evidence supports this view. For example, abnormal visual input during infancy caused by misaligned eyes or congenital cataracts produces a permanent deficit in visual acuity, known as amblyopia (Lewis and Maurer, 2009). Unmatched input from the two eyes early in life not only results in loss of vision in the amblyopic eye but also disrupts the typical binocular organization of thalamo-cortical afferents, also known as ocular dominance columns. If the perturbation occurs later or in adulthood, the deficits are milder or nonexistent (Hubel and Wiesel, 1970). The notion of heightened periods of brain plasticity during development is not limited to sensory systems, but also extends to motor functions or cognition such as language acquisition (Newport et al., 2001). Here, we focus on amblyopia (from the Greek, amblyos-blunt; opia_-vision) as an example of enduring changes in response to early experience (Ciuffreda et al., 1991).

Recent work has begun to unravel the cellular and molecular constraints that limit recovery from amblyopia, identifying two main classes of "brakes" that emerge with development (Fig. 1).

Received Sept. 13, 2010; revised 0ct. 11, 2010; accepted 0ct. 14, 2010.

This work was supported in part by the McDonnell Foundation, "Critical Period Revisited Network" to D.B., D.M.L., and T.K.H., as well by National Eye Institute (NEI) Grants EY016880 to D.B., EYR010178 to D.M.L., and R01EY020976 to D.M.L. and D.B., and the Ellison Medical Foundation to T.H., and NEI Grant EY18861 to Y.D. We thank T. Jacques for his creative efforts in figure development and for his invaluable help in manuscript preparation.

Correspondence should be addressed to Daphne Bavelier, Department of Brain and Cognitive Sciences, Meliora Hall-0268, University of Rochester, Rochester, NY 14627-0268. E-mail: daphne@cvs.rochester.edu.

DOI:10.1523/JNEUROSCI.4812-10.2010

Copyright $\odot 2010$ the authors $\quad 0270-6474 / 10 / 3014964-08 \$ 15.00 / 0$
On the one hand, new structures established as the animal matures (e.g., myelin or perineuronal nets) drastically curtail neurite outgrowth in the adult brain. On the other hand, functional changes in the balance between excitation and inhibition (E/I) directly regulate the plastic potential of the established neural network. To date, this work has been predominantly performed in animal models. Yet, in addition to its theoretical importance, it is of high practical significance for humans, as it paves the way for new approaches to functional rehabilitation following cortical damage in adulthood and to promote learning by education and in job training. A challenge is to translate the biological manipulations shown to be effective in rodents into feasible and safe interventions in humans. With this aim, we consider the impact of perceptual learning and entertainment video games as tools that may promote brain plasticity.

\section{"Brakes" on plasticity and how to lift them}

An emerging view is that the brain is intrinsically plastic, and one of the outcomes of normal development is then to stabilize the neural networks that are initially sculpted by experience during the sensitive period. In the case of early vision, a key role of one such period is for visual experience to consolidate spatial acuity and to enforce the matching of orientation preference in binocular cells through the two eyes (Wang et al., 2010). More generally, a reduction in plasticity as development proceeds is likely to allow greater adaptability of the organism to variable conditions early in life, while ensuring an efficient neural architecture for known conditions by adulthood.

Early in development, excitation appears to dominate cortical circuits, but accumulating evidence supports a pivotal role for late-developing E/I circuit balance in the initiation of sensitive periods (Fig. 1). For example, the onset of visual cortical plasticity is delayed by genetic disruption of GABA synthesis or a slowing 
(1)

Removing structural brakes

(2)

Re-setting E-I balance -

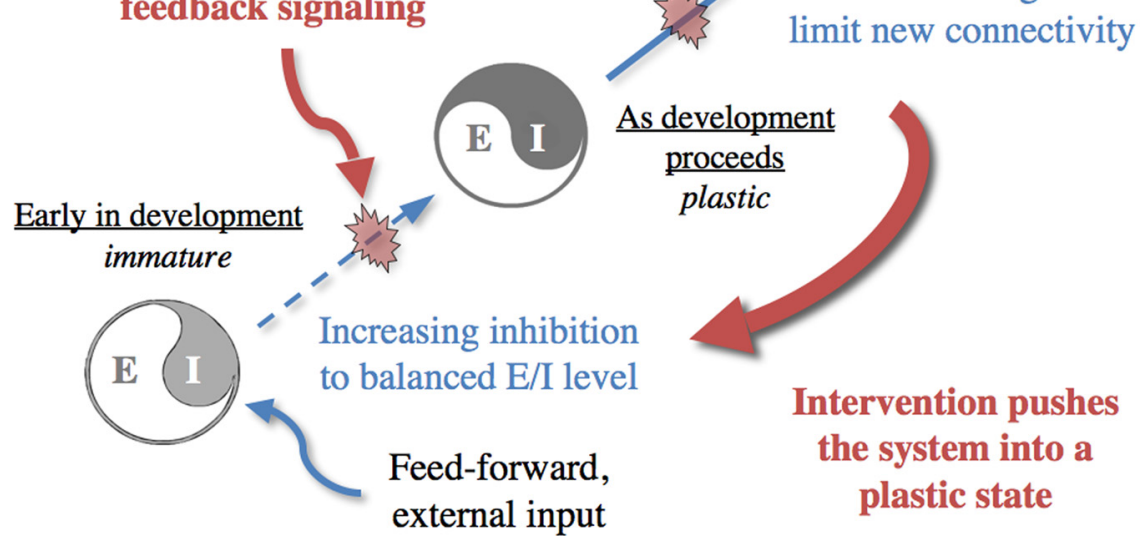

Figure 1. Evolving plastic capacity across the lifespan (blue arrows) (E/l, Excitatory-inhibitory circuit balance) suggests possible mechanisms for enhancing learning and recovery of function in adulthood (red). (1), Removing structural barriers to rewiring by targeting, for example, perineuronal nets, myelin, or epigenetic status. While effective in resetting brain plasticity in animal models (Table 1), their potential utility in humans remains elusive. (2), Resetting local E/I to a juvenile state where excitation dominates can also effectively promote plasticity in adulthood (Table 1). Noninvasive manipulations, such as the immersive and enriched conditions of video game play, may elicit various neuromodulatory responses, perhaps through feedback signals from higher control centers, to engage brain plasticity and learning in adults.

down of the maturational state of perisomatic inhibition (Hensch, 2005). Conversely, the application of benzodiazepines or other treatments that accelerate GABA circuit function triggers premature plasticity (Di Cristo et al., 2007; Sugiyama et al., 2008). These manipulations are so powerful that animals of identical chronological age may be at the peak, before, or past their sensitive period, depending on how the maturational state of their GABA circuitry has been altered.

Once induced, synaptic rewiring appears to be executed by the action of extracellular proteases (Mataga et al., 2002; Oray et al., 2004), which induce dendritic spine motility and pruning before regrowth. Notably, these effects proceed in a laminar sequence (Oray et al., 2004) consistent with the progression of plasticity through the thalamocortical circuit (Trachtenberg et al., 2000). Likewise in barrel cortex, a brief sensitive period for whisker receptive field tuning emerges concurrent with an increase in experience-dependent spine motility (Lendvai et al., 2000; Stern et al., 2001). Such abrupt and transient circuit reconfiguration is eventually recalibrated by homeostatic processes (Pozo and Goda, 2010), involving cell-intrinsic transcription factors (Greer and Greenberg, 2008; Chang et al., 2010) or surrounding gliaderived factors such as tumor necrosis factor $\alpha$ or the complement cascade (Stevens et al., 2007; Kaneko et al., 2008). It is notable in this context that one of the first successful approaches to reintroduce juvenile plasticity in the adult visual cortex was the direct transplantation of immature astrocytes (Müller and Best, 1989).

In addition, GABA circuits themselves exhibit synaptic plasticity that appears distinct from that of neighboring excitatory neurons (Yazaki-Sugiyama et al., 2009; Kameyama et al., 2010; Maffei et al., 2010). Whereas the classically studied pyramidal cell gradually shifts its responsiveness away from a deprived input, interneurons do so only later (Gandhi et al., 2008), and in the case of fast-spiking interneurons, after an initial shift toward the deprived input (Yazaki-Sugiyama et al., 2009). Remarkably, direct transplantation of embryonic GABA precursor cells in the postnatal brain also supports a second sensitive period (Southwell et al., 2010). Similar to normal development (Sugiyama et al., 2008), the second wave of plasticity only emerges once the transplant matures to a critical stage of connectivity, and not before or after.

Neural networks thus sculpted by early experience ultimately become more hardwired (Shatz and Stryker, 1978; Knudsen, 2004; Feldman and Brecht, 2005). Plasticity gradually winds down with a characteristic duration proportional to a species' lifespan (Berardi et al., 2000). Effects of early experience are thus actively preserved throughout life as a consequence of late-appearing molecular factors. The establishment of new connectivity may in part be under the control of "structural" factors that regulate axonal growth (Fig. 1), such as myelin-related proteins inhibiting axonal sprouting (NgR, PirB) (McGee et al., 2005; Syken et al., 2006) or chondroitin sulfate proteoglycans. The latter may restrain synaptic inputs by forming tight perineuronal nets (PNNs) (Pizzorusso et al., 2006; Carulli et al., 2010) around the basket-type GABA cells which normally initiate a sensitive period (above). Directly removing such physical barriers to plasticity enables recovery from amblyopia (Table 1) (H. Morishita, M. Chung, H. Miyamoto, Z. He, M. Fagiolini, and T. K. Hensch, unpublished observations).

Alternatively, the plastic potential of neural networks can be engaged late in life by acutely regulating "functional" E/I transmitter release. Manipulations that locally reduce inhibition in adulthood have been found to restore a heightened visual plasticity (He et al., 2007; Sugiyama et al., 2008; Harauzov et al., 2010) (Fig. 1). One action of endogenous neuromodulator release such as norepinephrine, acetylcholine, serotonin, or dopamine may be to adjust a favorable E/I balance (Bear and Singer, 1986; Kasamatsu, 1991; Kilgard and Merzenich, 1998; Bao et al., 2001; Weinberger, 2007; Maya Vetencourt et al., 2008; Goard and Dan, 2009). In a striking example, chronic treatment with the serotonin reuptake inhibitor (SSRI) fluoxetine restores visual function in amblyopic adult rats apparently by resetting E/I balance (Maya Vetencourt et al., 2008). This neurochemical milieu can act in a cell-specific manner during periods of heightened arousal or focal attention (McCormick, 1989; Gil et al., 1997; Kawaguchi, 1997; Kawaguchi and Shindou, 1998; Xiang et al., 1998; Hsieh et al., 2000; Froemke et al., 2007). Neuromodulatory tone also underlies sleep-wake state, fluctuating with a diurnal rhythm and providing a potential link to the regulatory role of sleep on brain plasticity (Frank et al., 2001; Steriade, 2004).

Interestingly, even these permissive factors are tightly regulated throughout the lifespan. Intense stimulation of neuromodulatory systems during infancy leads to impaired ability to augment learning later in life (Liang et al., 2006). In the mature brain, brake-like molecules further limit the role of neuromodu- 
Table 1. Summary of invasive and noninvasive interventions that either induce ocular dominance shifts in adults with normal vision ("Adult ODP") or restore visual acuity in adulthood ("Recovery")

\begin{tabular}{|c|c|c|c|c|c|}
\hline Intervention & Mechanism & Adult ODP & Recovery & Species & References \\
\hline \multicolumn{6}{|l|}{ Invasive } \\
\hline Astrocyte transplant & Structural & $\sqrt{ }$ & n.t. & Cat & Müller and Best (1989) \\
\hline NGF infusion & Structural & $\sqrt{ }$ & n.t. & Cat & Gu et al. (1994); Galuske et al. (2000) \\
\hline $\operatorname{chABC}$ & Structural & $\sqrt{ }$ & $\sqrt{ }$ & Rat & Pizzorusso et al. $(2002,2006)$ \\
\hline Crtl1 KO & Structural & $\sqrt{ }$ & n.t. & Mouse & Carulli et al. (2010) \\
\hline $\mathrm{NgR} \mathrm{KO}$ & Structural & $\sqrt{ }$ & $\sqrt{ }$ & Mouse & $\begin{array}{l}\text { McGee et al. (2005); H. Morishita, M. Chung, H. Miyamoto, Z. He, M. Fagiolini, } \\
\text { and T. K. Hensch (unpublished observations) }\end{array}$ \\
\hline PirB KO & Structural & $\sqrt{ }$ & n.t. & Mouse & Syken et al. (2006) \\
\hline $\mathrm{dnNgR}$ & Structural & $\sqrt{ }$ & n.t. & Mouse & $\begin{array}{l}\text { H. Morishita, M. Chung, H. Miyamoto, Z. He, M. Fagiolini, } \\
\text { and T. K. Hensch (unpublished observations) }\end{array}$ \\
\hline Focal demyelination & Structural & $\sqrt{ }$ & $\sqrt{ }$ & Mouse & $\begin{array}{l}\text { H. Morishita, M. Chung, H. Miyamoto, Z. He, M. Fagiolini, } \\
\text { and T. K. Hensch (unpublished observations) }\end{array}$ \\
\hline Locus ceruleus stimulation & $E / I$ & $\sqrt{ }$ & n.t. & Cat & Kasamatsu et al. (1985) \\
\hline cAMP activation & $E / I$ & $\sqrt{ }$ & n.t. & Cat & Imamura et al. (1999) \\
\hline MGE transplant & $E / I$ & $\sqrt{ }$ & n.t. & Mouse & Southwell et al. (2010) \\
\hline Lynx1 K0 & $E / I$ & $\sqrt{ }$ & $\sqrt{ }$ & Mouse & Morishita et al. (2010) \\
\hline \multicolumn{6}{|l|}{ Noninvasive } \\
\hline Valproic acid/TSA & Structural & $\sqrt{ }$ & $\sqrt{ }$ & Rat/mouse & Putignano et al. (2007); Silingardi et al. (2010) \\
\hline AChase inhibitor & $E / I$ & $\sqrt{ }$ & $\sqrt{ }$ & Mouse & Morishita et al. (2010) \\
\hline Fluoxetine & $E / I$ & $\sqrt{ }$ & $\sqrt{ }$ & Rat & Maya Vetencourt et al. (2008) \\
\hline L-threo-DOPS & $E / I$ & $\sqrt{ }$ & n.t. & Cat & Mataga et al. (1992) \\
\hline Dark exposure & $E / I$ & $\sqrt{ }$ & $\sqrt{ }$ & Rat & He et al. (2007) \\
\hline Enrichment & $E / I$ & $\sqrt{ }$ & $\sqrt{ }$ & Rat & Sale et al. (2007) \\
\hline Perceptual learning & $E / I$ & n.t. & $\sqrt{ }$ & Human & Levi and Li (2009b) \\
\hline Video games & $E / I$ & n.t. & $\sqrt{ }$ & Human & Li et al. (2010) \\
\hline TMS & $E / I$ & n.t. & $\sqrt{ }$ & Human & Thompson et al. (2008) \\
\hline
\end{tabular}

Proposed mechanism is categorized as disruption of structural or functional brakes. n.t., Not tested; chABC, chondroitinase ABC; NGF, nerve growth factor; L-threo-DOPS, L-threo-dihydroxyphenylserine; KO, knockout; Crtl1, cartilage link protein; NgR, Nogo receptor; PirB, paired immunoglobulin-like receptor B; dnNgR, dominant-negative NgR; MGE, medial ganglionic eminence; TSA, trichostatin A; AChase, acetyl-cholinesterase; TMS, transcranial magnetic stimulation.

lators on brain plasticity. One such factor is the prototoxin Lynx1 acting on nicotinic receptors to dampen the response to acetylcholine. Removal of Lynx1 restores plasticity and allows recovery from amblyopia in adulthood (Morishita et al., 2010). Plastic changes induced in adulthood can be qualitatively different from those of the juvenile (Frenkel and Bear, 2004; Sato and Stryker, 2008), and may not always be enduring or capable of fully overcoming the structural limitations established earlier during sensitive periods. Yet, under certain conditions, they are adequate to restore enough plasticity to reverse amblyopia (Table 1).

\section{Lessons for brain plasticity in adult humans}

There is no doubt that humans demonstrate marked learning as a result of practice even in adulthood; yet when compared with children, adult learning appears qualitatively and quantitatively different. It is effortful, often quite narrow in its scope, and most of the time incomplete compared with the learning children may exhibit (Newport et al., 2001). Recent animal studies focused on augmenting plasticity in the visual cortex have identified means to recapitulate juvenile forms of learning in adulthood (Table 1). Achieving the same in humans would be a significant clinical advance as amblyopia is not always reversed when treated early in development, and conventional strategies (patching and penalization) are generally not undertaken in older children and adults. Here, we ask how the brakes identified in animal research might be lifted in humans, keeping in mind the possible costs of inducing exuberant plasticity in a mature nervous system.

One rather drastic example of adult plasticity in the case of amblyopia comes from "experiments of nature" whereby amblyopic patients have lost vision in the "good" eye. Under these conditions, visual acuity in the amblyopic eye sometimes spontaneously improves (Vereecken and Brabant, 1984; El Mallah et al., 2000; Rahi et al., 2002). These few reports are consistent with the notion that the connections from the amblyopic eye may be weakened, inhibited, or unattended, rather than destroyed. Loss of the fellow eye would allow these existing connections to be reactivated. This could be the result of unmasking (Restani et al., 2009) or higher brain areas learning to attend to the previously inhibited signals from the amblyopic eye.

While direct pharmacological manipulations in humans are theoretically appealing, indiscriminately tampering with brakes on plasticity throughout the brain may cause more harm than good (see Pascual-Leone et al., 2005 for the two sides of plasticity). Interfering with brain chemistry, as in most animal studies, raises significant ethical and safety concerns. At the same time, many FDA-approved drugs are already administered with potentially informative side effects. This is the case, for example, of valproic acid and benzodiazepines. Recovery from stroke is enhanced by factors hypothesized to promote brain plasticity (Moskowitz et al., 2010), and could therefore potentially benefit from such a pharmacological approach.

Drugs that alter the "epigenome" also hold promise given recent discoveries of how environmental changes alter brain chromatin status (Zhang and Meaney, 2010). Epigenetic modifications, such as the acetylation of histones, are a common target of cancer biology (Stimson et al., 2009), and may have profound impact on the regulation of behavior. Histone deacetylase inhibitors promote synaptic plasticity (Levenson and Sweatt, 2006), reactivate critical periods, and rescue amblyopia in adult rodents (Putignano et al., 2007; Silingardi et al., 2010). More generally, the use of drugs that specifically target transcriptional regulatory processes known to be altered in neurodevelopmental disorders, such as Down's syndrome, fragile X, or Rett's syndrome, to cite a few, has proven strikingly efficient at alleviating cognitive deficits even when administered in adulthood (Chahrour and Zoghbi, 
2007; Ehninger et al., 2008; Greer and Greenberg, 2008). Consistent with the theme developed here (Morishita and Hensch, 2008), one purported mechanism of action of these drugs may be to restore a more normal E/I balance (which is commonly impaired in such disorders) (Rubenstein and Merzenich, 2003; Polleux and Lauder, 2004; Gogolla et al., 2009).

Results from animal studies reviewed in Table 1 further suggest a need to systematically document psychotropic medications (e.g., SSRI antidepressants). In a close parallel with the animal literature, clinical trials to treat amblyopia with fluoxetine are underway in Finland, India, and New Zealand (L. Maffei, personal communication). Likewise, direct enhancement of cortical processing by cholinesterase inhibitors (Silver et al., 2008), such as those prescribed for Alzheimer's disease, offers another opportunity. Yet, it would be ideal to endogenously recapitulate brain states conducive to plasticity in a noninvasive but targeted manner. One potential route is through the endogenous release of permissive factors in response to altered environments.

The proposal that brain plasticity and learning are fostered by environmental factors is far from new (Greenough et al., 1987). As early as the 1960s, Bennett et al. (1964) had noted that adult rats housed in enriched cages had a greater cortical weight than those housed in individual, standard laboratory cages. Two seemingly opposite manipulations in adult rats illustrate the power of environment. Oddly, amblyopic rats subjected to complete visual deprivation by dark exposure for $10 \mathrm{~d}$ recover significant vision once allowed to see binocularly (He et al., 2007). Translation of this treatment to humans is questionable as the proportional length of dark exposure required is likely to be on the order of months rather than days, which may be too disruptive for most.

Arguably, a second, more promising approach for humans is environmental enrichment. Rats forced to use their amblyopic eye after reverse suture benefit from an exercise wheel, larger social groups, daily repositioning of food hoppers and various objects, and weekly cage changing (Sale et al., 2007). In both cases, a common mechanism is implicated-a change in E/I balance through reduced GABAergic inhibition in the visual cortex. In a parallel to these findings, recent work in humans has identified behavioral interventions that may heighten brain plasticity, above and beyond that observed under a normal lifestyle.

One such environment is aerobic exercise. The positive effects of aerobic exercise are particularly well known in the field of aging, with individuals who normally exercise outperforming those who do not on tasks as varied as dual-task performance, executive attention, or distractor rejection (for recent reviews, see Colcombe and Kramer, 2003; Kramer and Erickson, 2007; Hillman et al., 2008). In addition to its well documented impact on neurogenesis in animal models (Kempermann et al., 2000; Nithianantharajah and Hannan, 2006), aerobic fitness also leads to neuroanatomical and neurophysiological changes in older adults, including increased gray matter volume in the prefrontal and temporal areas (Colcombe and Kramer, 2003) and functional brain activity in a variety of areas such as superior parietal areas and the anterior cingulate cortex (Colcombe et al., 2004). Whether aerobic exercise can enhance brain plasticity in healthy, young adults unfortunately remains undocumented.

Another type of enriched environment extensively studied in humans, especially in the case of vision, is perceptual learning and, more recently, immersion in video games. During perceptual learning using only their amblyopic eye, patients are required to practice a variety of visual tasks. A review of the extant studies (almost 200 amblyopic subjects distributed over 14 papers) reveals that such practice results in a long-lasting improvement in performance in amblyopic eyes (Levi and Li, 2009a). It is generally strongest for the trained eye, task, stimulus, and orientation, but appears to improve over a broader spatial frequency bandwidth than in normal vision, indicating some level of transfer (Huang et al., 2008). So far, perceptual learning has had limited impact on clinical practice, however, because of its limited transfer and the rather dull nature of the training, leading to compliance issues. Yet, the mechanisms by which it operates - a reduction of internal neural noise and/or more efficient use of the stimulus information by retuning the weighting of the information-are central to changing information processing in the visual cortex (Li et al., 2008; Levi and Li, 2009a).

Similarly, recent studies indicate that enhancements after action video game play are also due to observers being better able to select and use the most reliable information for the task ( $\mathrm{Li}$ et al., 2009a). Yet, unlike perceptual learning, whereby the observer typically learns the best template just for the trained task, this work suggests that action gamers learn to find the best template on the fly as they are faced with new visual stimuli and new environments (Green et al., 2010b). Accordingly, fast-paced, action-packed games have already been documented to have potent positive impact on an array of skills, including perception, visuo-motor coordination, spatial cognition, attention, and decision making to cite a few, illustrating the powerful effect of action game play in reshaping the adult brain (Gagnon, 1985; Dorval and Pépin, 1986; Greenfield et al., 1994; De Lisi and Wolford, 2002; Green and Bavelier, 2006; Quaiser-Pohl et al., 2006; Greenfield, 2009; Li et al., 2009b).

Having access to a training regimen that naturally leads to improvements across many different visual tasks would be highly beneficial, as amblyopes suffer not only from low-level vision losses, but also from higher-level vision losses (for review, see Kiorpes, 2006; Levi, 2006). With an eye toward these mechanisms, adults with amblyopia were recently asked to play an offthe-shelf action video game (Medal of Honor: Pacific Assault) with their fellow eye patched (Li et al., 2010). This resulted in a substantial improvement in a wide range of fundamental visual functions, from low-level to high-level, including visual acuity, positional acuity, visual attention, and stereopsis.

Interestingly, improvement in amblyopic vision was also noted after playing non-action video games such as SimCity, which are not efficient in boosting normal vision ( $\mathrm{Li}$ et al., 2009 b). This observation is consistent with a primary principle in the field of learning wherein the learner should be faced with the "just-right" challenge to produce the greatest benefits. While the high demands of action games may be needed to push the limits of normal vision, less visually intense games may be a sufficient challenge to enhance amblyopic vision (see, for example, $\mathrm{Vy}$ gotsky's (1978) Zone of Proximal Development). Consistent with this, normal rats do not improve their vision further in the same enriched cages that adequately restore acuity to their amblyopic siblings (Sale et al., 2007), and may rather require more extreme enrichment. The possibility of immersing rats into virtual environments should open the door to such studies (Harvey et al., 2009).

Action video game play may therefore improve the efficiency of probabilistic inference in neural circuits, which in turn would provide a mechanistic explanation for the broad transfer such training engenders (Green et al., 2010b). These plastic changes have been shown to be long-lasting, with beneficial effects noted 6 months to 2 years after the end of intervention (Feng et al., 2007; Li et al., 2009b). As with enriched cages, the factors that conspire to induce brain plasticity within the action game expe- 
rience remain to be systematically assessed. As a training paradigm, gaming differs from more standard methods on several dimensions. First, gaming tends to be more varied in the skills it requires than standard training, which typically focuses on just one aspect of performance, as exemplified in the field of perceptual learning. Such variation during training enhances transfer across tasks (Schmidt and Bjork, 1992; Kornell and Bjork, 2008). Second, unlike standard training paradigms, gaming is an activity that is highly engrossing and also extremely rewarding. Reward, and the drive to perform as many correct responses per unit of time (Dye et al., 2009a), is likely to engage dopamine and possibly opiates and other neuromodulators. The relationship between game play and the reward system remains, however, an understudied domain. An early PET study indicated a large release of striatal dopamine during the play of a toy video game (Koepp et al., 1998), but significant experimental bias can affect the estimated size of the effect, calling for further replications (Egerton et al., 2009). Third, action games constantly require divided attention and its efficient reallocation as task demands change, most likely engaging neuromodulatory systems such as acetylcholine and dopamine (Rueda et al., 2005; Dye et al., 2009b), which are also known to enhance sensory processing and brain plasticity (Kilgard and Merzenich, 1998; Bao et al., 2001; Goard and Dan, 2009).

Finally, gaming is also associated with "flow" or the sense that one is able to meet the challenges of one's environment with appropriate skills (Csikszentimihalyi, 1990). Flow is also characterized by a deep sense of enjoyment which goes beyond satisfying a need, and rather occurs when a person achieves something unexpected that has a sense of novelty. Playing entertainment video games is likely to increase flow. Accordingly, older adult stroke survivors report that participating in a virtual reality rehabilitation program leads to increased involvement, enjoyment, and sense of control over the environment (Farrow and Reid, 2004). The physiological bases of flow remain largely unknown, yet it would seem key for further studies to understand how it engages neuromodulatory systems as well as the regulation of the autonomous nervous system (Tang et al., 2007; Lutz et al., 2008).

\section{Concluding remarks and future directions}

Biology of the brain is heavily invested in the optimal timing and duration of plasticity, having evolved numerous molecular checks and balances to ensure an adaptable yet efficient organism. As we gain better knowledge of these mechanisms, we can assess the extent to which a sensitive period can be safely and noninvasively recapitulated by behavioral training such as perceptual learning (Levi and Li, 2009b), video game play (Green et al., 2010a), targeted pharmacological manipulation (Fluoxetine), or even brain stimulation to alter E/I balance directly (Fregni and Pascual-Leone, 2007; Thompson et al., 2008). A main challenge will be the ability to foster plasticity and relearning in one domain, while leaving unaltered cortical functions in other domains.

Physically constraining neuronal networks in a "sea" of molecular brakes after an early sensitive period may ensure that the widespread functional tuning driven by experience during development is maintained. Yet, the nervous system retains the ability to further retune its functional specificity even in adulthood, albeit in a more local and specific manner, through permissive, feedback factors such as neuromodulators (Fig. 1). Higher-level brain circuits involved in attention, executive function, and behavior regulation may play a pivotal role in adult plasticity by their ability to modulate the coding efficiency of lower-order networks.

For instance, endogenous GABA circuits in superficial cortical layers seem to retain a latent plasticity throughout life (Lee et al., 2008; Kameyama et al., 2010). These may be poised to tap topdown feedback from higher cortical areas to sensory-motor structures such as during attentional tasks (Chen et al., 2008). Similarly, cholinergic projections from the basal forebrain to the neocortex, which have been shown to enhance the efficiency of sensory coding (Goard and Dan, 2009), may act by selectively modulating different GABAergic subtypes (Kawaguchi, 1997; Xiang et al., 1998; Kruglikov and Rudy, 2008). Such top-down control of adult plasticity would allow for fine-tuning of network connectivity as experience and demands from the environment varies, while still maintaining the overall circuit stability that typically follows the sensitive period.

The widespread learning and plasticity observed in response to action video games may provide a shared model system with which to study adult plasticity in animals and humans. A viable working hypothesis is that action game play primarily impacts top-down, attentional systems (Hubert-Wallander et al., 2010), possibly altering the E/I balance to allow heightened plasticity. Simulations of artificial networks of spiking neurons accordingly indicate that the efficiency of neural coding is enhanced thanks to changes in synaptic weights (Green et al., 2010b). It will be essential to learn, however, whether video games are engaging a topdown unmasking (Yang and Maunsell, 2004; Wandell and Smirnakis, 2009), perhaps variably effective depending on the circuitry established by each individual's past experience, or in fact truly allow for plastic reorganization. In particular, whether structural brakes (gray matter myelin, PNNs) are lifted by video game training, enabling the physical pruning and growth of new axons in $\mathrm{V} 1$, remains uncertain and will require the improved resolution of imaging techniques (Karaarslan and Arslan, 2003; Thomas et al., 2008; Bock et al., 2009).

The links between action video game play and the molecular and cellular factors that control plasticity in animal models are quite preliminary. Human studies of learning and brain plasticity typically focus on changes in information processing and its efficiency, whereas animal studies characterize the molecular and cellular mechanisms that allow changes in connectivity. A more complete understanding of brain plasticity calls for bringing together these two levels of investigation within the same model system. These should be fruitful steps to further our understanding of the physiological states that promote brain plasticity and learning.

\section{References}

Bao S, Chan VT, Merzenich MM (2001) Cortical remodelling induced by activity of ventral tegmental dopamine neurons. Nature 412:79-83.

Bear MF, Singer W (1986) Modulation of visual cortical plasticity by acetylcholine and noradrenaline. Nature 320:172-176.

Bennett EL, Diamond MC, Krech D, Rosenzweig MR (1964) Chemical and anatomical plasticity of brain: changes in brain through experience, demanded by learning theories, are found in experiments with rats. Science 146:610-619.

Berardi N, Pizzorusso T, Maffei L (2000) Critical periods during sensory development. Curr Opin Neurobiol 10:138-145.

Bock NA, Kocharyan A, Liu JV, Silva AC (2009) Visualizing the entire cortical myelination pattern in marmosets with magnetic resonance imaging. J Neurosci Methods 185:15-22.

Carulli D, Pizzorusso T, Kwok JC, Putignano E, Poli A, Forostyak S, Andrews MR, Deepa SS, Glant TT, Fawcett JW (2010) Animals lacking link protein have attenuated perineuronal nets and persistent plasticity. Brain 133:2331-2347. 
Chahrour M, Zoghbi HY (2007) The story of Rett Syndrome: from clinic to neurobiology. Neuron 56:422-437.

Chang MC, Park JM, Pelkey KA, Grabenstatter HL, Xu D, Linden DJ, Sutula TP, McBain CJ, Worley PF (2010) Narp regulates homeostatic scaling of excitatory synapses on parvalbumin-expressing interneurons. Nat Neurosci 13:1090-1097.

Chen Y, Martinez-Conde S, Macknik SL, Bereshpolova Y, Swadlow HA, Alonso JM (2008) Task difficulty modulates the activity of specific neuronal populations in primary visual cortex. Nat Neurosci 11:974-982.

Ciuffreda KJ, Levi DM, Selenow A (1991) Amblyopia: basic and clinical aspects. Stoneham, MA: Butterworth-Heinemann.

Colcombe S, Kramer AF (2003) Fitness effects on the cognitive function of older adults: a meta-analytic study. Psychol Sci 14:125-130.

Colcombe SJ, Kramer AF, Erickson KI, Scalf P, McAuley E, Cohen NJ, Webb A, Jerome GJ, Marquez DX, Elavsky S (2004) Cardiovascular fitness, cortical plasticity, and aging. Proc Natl Acad Sci U S A 101:3316-3321.

Csikszentimihalyi M (1990) Flow: the psychology of optimal experience. New York: Harper.

De Lisi R, Wolford JL (2002) Improving children's mental rotation accuracy with computer game playing. J Genet Psychol 163:272-282.

Di Cristo G, Chattopadhyaya B, Kuhlman SJ, Fu Y, Bélanger MC, Wu CZ, Rutishauser U, Maffei L, Huang ZJ (2007) Activity-dependent PSA expression regulates inhibitory maturation and onset of critical period plasticity. Nat Neurosci 10:1569-1577.

Dorval M, Pépin M (1986) Effect of playing a video game on a measure of spatial visualization. Percept Mot Skills 62:159-162.

Dye MW, Green CS, Bavelier D (2009a) Increasing speed of processing with action video games. Curr Dir Psychol Sci 18:321-326.

Dye MW, Green CS, Bavelier D (2009b) The development of attention skills in action video game players. Neuropsychologia 47:1780-1789.

Egerton A, Mehta MA, Montgomery AJ, Lappin JM, Howes OD, Reeves SJ, Cunningham VJ, Grasby PM (2009) The dopaminergic basis of human behaviors: a review of molecular imaging studies. Neurosci Biobehav Rev 33:1109-1132.

Ehninger D, Li W, Fox K, Stryker MP, Silva AJ (2008) Reversing neurodevelopmental disorders in adults. Neuron 60:950-960.

El Mallah MK, Chakravarthy U, Hart PM (2000) Amblyopia: is visual loss permanent? Br J Ophthalmol 84:952-956.

Farrow S, Reid D (2004) Stroke survivors' perceptions of a leisure-based virtual reality system. Technol Disabil 16:69-81.

Feldman DE, Brecht M (2005) Map plasticity in somatosensory cortex. Science 310:810-815.

Feng J, Spence I, Pratt J (2007) Playing an action videogame reduces gender differences in spatial cognition. Psychol Sci 18:850-855.

Frank MG, Issa NP, Stryker MP (2001) Sleep enhances plasticity in the developing visual cortex. Neuron 30:275-287.

Fregni F, Pascual-Leone A (2007) Technology insight: noninvasive brain stimulation in neurology-perspectives on the therapeutic potential of rTMS and tDCS. Nat Rev Neurol 3:383-393.

Frenkel MY, Bear MF (2004) How monocular deprivation shifts ocular dominance in visual cortex of young mice. Neuron 44:917-923.

Froemke RC, Merzenich MM, Schreiner CE (2007) A synaptic memory trace for cortical receptive field plasticity. Nature 450:425-429.

Gagnon D (1985) Videogame and spatial skills: an exploratory study. Educ Commun Technol J 33:263-275.

Galuske RA, Kim DS, Castrén E, Singer W (2000) Differential effects of neurotrophins on ocular dominance plasticity in developing and adult cat visual cortex. Eur J Neurosci 12:3315-3330.

Gandhi SP, Yanagawa Y, Stryker MP (2008) Delayed plasticity of inhibitory neurons in developing visual cortex. Proc Natl Acad Sci U S A 105:16797-16802.

Gil Z, Connors BW, Amitai Y (1997) Differential regulation of neocortical synapses by neuromodulators and activity. Neuron 19:679-686.

Goard M, Dan Y (2009) Basal forebrain activation enhances cortical coding of natural scenes. Nat Neurosci 12:1444-1449.

Gogolla N, Leblanc JJ, Quast KB, Südhof TC, Fagiolini M, Hensch TK (2009) Common circuit defect of excitatory-inhibitory balance in mouse models of autism. J Neurodev Disord 1:172-181.

Green CS, Bavelier D (2006) The cognitive neuroscience of video games. In: Digital media: transformations in human communication (Humphreys L, Messaris P, eds), pp 211-224. New York: Peter Lang Publishing.
Green CS, Li R, Bavelier D (2010a) Perceptual learning during action video games. Topics Cogn Sci 2:202-216.

Green CS, Pouget A, Bavelier D (2010b) Improved probabilistic inference as a general learning mechanism with action video games. Curr Biol 20:1573-1579.

Greenfield PM (2009) Technology and informal education: what is taught, what is learned. Science 323:69-71.

Greenfield PM, DeWinstanley P, Kilpatrick H, Kaye D (1994) Action video games and informal education: effects on strategies for dividing visual attention. J Appl Dev Psychol 15:105-123.

Greenough WT, Black JE, Wallace CS (1987) Experience and brain development. Child Dev 58:539-559.

Greer PL, Greenberg ME (2008) From synapse to nucleus: calciumdependent gene transcription in the control of synapse development and function. Neuron 59:846-860.

Gu Q, Liu Y, Cynader MS (1994) Nerve growth factor-induced ocular dominance plasticity in adult cat visual cortex. Proc Natl Acad Sci U S A 91:8408-8412.

Harauzov A, Spolidoro M, DiCristo G, De Pasquale R, Cancedda L, Pizzorusso T, Viegi A, Berardi N, Maffei L (2010) Reducing intracortical inhibition in the adult visual cortex promotes ocular dominance plasticity. J Neurosci 30:361-371.

Harvey CD, Collman F, Dombeck DA, Tank DW (2009) Intracellular dynamics of hippocampal place cells during virtual navigation. Nature 461:941-946.

He HY, Ray B, Dennis K, Quinlan EM (2007) Experience-dependent recovery of vision following chronic deprivation amblyopia. Nat Neurosci 10:1134-1136.

Hensch TK (2005) Critical period plasticity in local cortical circuits. Nat Rev Neurosci 6:877-888.

Hillman CH, Erickson KI, Kramer AF (2008) Be smart, exercise your heart: exercise effects on brain and cognition. Nat Rev Neurosci 9:58-65.

Hsieh CY, Cruikshank SJ, Metherate R (2000) Differential modulation of auditory thalamocortical and intracortical synaptic transmission by cholinergic agonist. Brain Res 880:51-64.

Huang CB, Zhou Y, Lu ZL (2008) Broad bandwidth of perceptual learning in the visual system of adults with anisometropic amblyopia. Proc Natl Acad Sci U S A 105:4068-4073.

Hubel DH, Wiesel TN (1970) The period of susceptibility to the physiolog ical effects of unilateral eye closure in kittens. J Physiol 206:419-436.

Hubert-Wallander BP, Green CS, Bavelier D 2010 Stretching the limits of visual attention: the case of action video games. WIREs Cogn Sci. Advance online publication. doi:10.1002/wcs.116.

Imamura K, Kasamatsu T, Shirokawa T, Ohashi T (1999) Restoration of ocular dominance plasticity mediated by adenosine $3^{\prime}, 5^{\prime}$-monophosphate in adult visual cortex. Proc Biol Sci 266:1507-1516.

Kameyama K, Sohya K, Ebina T, Fukuda A, Yanagawa Y, Tsumoto T (2010) Difference in binocularity and ocular dominance plasticity between GABAergic and excitatory cortical neurons. J Neurosci 30:1551-1559.

Kaneko M, Stellwagen D, Malenka RC, Stryker MP (2008) Tumor necrosis factor- $\alpha$ mediates one component of competitive, experience-dependent plasticity in developing visual cortex. Neuron 58:673-680.

Karaarslan E, Arslan A (2003) Perirolandic cortex of the normal brain: low signal intensity on turbo FLAIR MR images. Radiology 227:538-541.

Kasamatsu T (1991) Adrenergic regulation of visuocortical plasticity: a role of the locus coeruleus system. Prog Brain Res 88:599-616.

Kasamatsu T, Watabe K, Heggelund P, Schöller E (1985) Plasticity in cat visual cortex restored by electrical stimulation of the locus coeruleus. Neurosci Res 2:365-386.

Kawaguchi Y (1997) Selective cholinergic modulation of cortical GABAergic cell subtypes. J Neurophysiol 78:1743-1747.

Kawaguchi Y, Shindou T (1998) Noradrenergic excitation and inhibition of GABAergic cell types in rat frontal cortex. J Neurosci 18:6963-6976.

Kempermann G, van Praag H, Gage FH (2000) Activity-dependent regulation of neuronal plasticity and self repair. Prog Brain Res 127:35-48.

Kilgard MP, Merzenich MM (1998) Cortical map reorganization enabled by nucleus basalis activity. Science 279:1714-1718.

Kiorpes L (2006) Visual processing in amblyopia: animal studies. Strabismus 14:3-10.

Knudsen EI (2004) Sensitive periods in the development of the brain and behavior. J Cogn Neurosci 16:1412-1425.

Koepp MJ, Gunn RN, Lawrence AD, Cunningham VJ, Dagher A, Jones T, 
Brooks DJ, Bench CJ, Grasby PM (1998) Evidence for striatal dopamine release during a video game. Nature 393:266-268.

Kornell N, Bjork RA (2008) Learning concepts and categories: is spacing the "enemy of induction"? Psychol Sci 19:585-592.

Kramer AF, Erickson KI (2007) Capitalizing on cortical plasticity: influence of physical activity on cognition and brain function. Trends Cogn Sci 11:342-348.

Kruglikov I, Rudy B (2008) Perisomatic GABA release and thalamocortical integration onto neocortical excitatory cells are regulated by neuromodulators. Neuron 58:911-924.

Lee WC, Chen JL, Huang H, Leslie JH, Amitai Y, So PT, Nedivi E (2008) A dynamic zone defines interneuron remodeling in the adult neocortex. Proc Natl Acad Sci U S A 105:19968-19973.

Lendvai B, Stern EA, Chen B, Svoboda K (2000) Experience-dependent plasticity of dendritic spines in the developing rat barrel cortex in vivo. Nature 404:876-881.

Levenson JM, Sweatt JD (2006) Epigenetic mechanisms: a common theme in vertebrate and invertebrate memory formation. Cell Mol Life Sci 63:1009-1016.

Levi DM (2006) Visual processing in amblyopia: human studies. Strabismus 14:11-19.

Levi DM, Li RW (2009a) Improving the performance of the amblyopic visual system. Philos Trans R Soc Lond B Biol Sci 364:399-407.

Levi DM, Li RW (2009b) Perceptual learning as a potential treatment for amblyopia: a mini-review. Vision Res 49:2535-2549.

Lewis TL, Maurer D (2009) Effects of early pattern deprivation on visual development. Optom Vis Sci 86:640-646.

Li R, Bejjanki VR, Lu ZL, Pouget A, Bavelier D (2009a) Playing action video games leads to better perceptual templates. Presented at the annual meeting of the Vision Sciences Society, Naples, FL, May.

Li R, Polat U, Makous W, Bavelier D (2009b) Enhancing the contrast sensitivity function through action video game training. Nat Neurosci 12:549-551.

Li RW, Ngo C, Nguyen J, Levi DM (2010) Video game play induces plasticity in the visual system of adults with amblyopia. PLoS Biol, in press.

Li RW, Klein SA, Levi DM (2008) Prolonged perceptual learning of positional acuity in adult amblyopia: perceptual template retuning dynamics. J Neurosci 28:14223-14229.

Liang K, Poytress BS, Chen Y, Leslie FM, Weinberger NM, Metherate R (2006) Neonatal nicotine exposure impairs nicotinic enhancement of central auditory processing and auditory learning in adult rats. Eur J Neurosci 24:857-866.

Lutz A, Slagter HA, Dunne JD, Davidson RJ (2008) Attention regulation and monitoring in meditation. Trends Cogn Sci 12:163-169.

Maffei A, Lambo ME, Turrigiano GG (2010) Critical period for inhibitory plasticity in rodent binocular V1. J Neurosci 30:3304-3309.

Mataga N, Imamura K, Watanabe Y (1992) L-threo-Dihydroxyphenylserine enhanced ocular dominance plasticity in adult cats. Neurosci Lett 142:115-118.

Mataga N, Nagai N, Hensch TK (2002) Permissive proteolytic activity for visual cortical plasticity. Proc Natl Acad Sci U S A 99:7717-7721.

Maya Vetencourt JF, Sale A, Viegi A, Baroncelli L, De Pasquale R, O'Leary OF, Castrén E, Maffei L (2008) The antidepressant fluoxetine restores plasticity in the adult visual cortex. Science 320:385-388.

McCormick DA (1989) Cholinergic and noradrenergic modulation of thalamocortical processing. Trends Neurosci 12:215-221.

McGee AW, Yang Y, Fischer QS, Daw NW, Strittmatter SM (2005) Experience-driven plasticity of visual cortex limited by myelin and Nogo receptor. Science 309:2222-2226.

Morishita H, Hensch TK (2008) Critical period revisited: Impact on vision. Curr Opin Neurobiol 18:101-107.

Morishita H, Miwa JM, Heintz N, Hensch TK (2010) Lynx1, a cholinergic brake limits plasticity in adult visual cortex. Science, in press.

Moskowitz MA, Lo EH, Iadecola C (2010) The science of stroke: Mechanisms in search of treatments. Neuron 67:181-198.

Müller CM, Best J (1989) Ocular dominance plasticity in adult cat visual cortex after transplantation of cultured astrocytes. Nature 342:427-430.

Newport EL, Bavelier D, Neville HJN (2001) Critical thinking about critical period: perspectives on a critical period for language acquisition. In: Language, brain and cognitive development: essays in honor of Jacques Mehler (Dupoux E, ed), pp 481-502. Boston: MIT.

Nithianantharajah J, Hannan AJ (2006) Enriched environments, experience- dependent plasticity and disorders of the nervous system. Nat Rev Neurosci 7:697-709.

Oray S, Majewska A, Sur M (2004) Dendritic spine dynamics are regulated by monocular deprivation and extracellular matrix degradation. Neuron 44:1021-1030.

Pascual-Leone A, Amedi A, Fregni F, Merabet LB (2005) The plastic human brain cortex. Annu Rev Neurosci 28:377-401.

Pizzorusso T, Medini P, Berardi N, Chierzi S, Fawcett JW, Maffei L (2002) Reactivation of ocular dominance plasticity in the adult visual cortex. Science 298:1248-1251.

Pizzorusso T, Medini P, Landi S, Baldini S, Berardi N, Maffei L (2006) Structural and functional recovery from early monocular deprivation in adult rats. Proc Natl Acad Sci U S A 103:8517-8522.

Polleux F, Lauder JM (2004) Toward a developmental neurobiology of autism. Ment Retard Dev Disabil Res Rev 10:303-317.

Pozo K, Goda Y (2010) Unraveling mechanisms of homeostatic synaptic plasticity. Neuron 66:337-351.

Putignano E, Lonetti G, Cancedda L, Ratto G, Costa M, Maffei L, Pizzorusso T (2007) Developmental downregulation of histone posttranslational modifications regulates visual cortical plasticity. Neuron 53:747-759.

Quaiser-Pohl C, Geiser C, Lehmann W (2006) The relationship between computer-game preference, gender, and mental-rotation ability. Pers Individ Dif 40:609-619.

Rahi J, Logan S, Timms C, Russell-Eggitt I, Taylor D (2002) Risk, causes, and outcomes of visual impairment after loss of vision in the nonamblyopic eye: a population-based study. Lancet 360:597-602.

Restani L, Cerri C, Pietrasanta M, Gianfranceschi L, Maffei L, Caleo M (2009) Functional masking of deprived eye responses by callosal input during ocular dominance plasticity. Neuron 64:707-718.

Rubenstein JL, Merzenich MM (2003) Model of autism: increased ration of excitation/inhibition in key neural systems. Genes Brain Behav 2:255-267.

Rueda MR, Rothbart MK, McCandliss BD, Saccomanno L, Posner MI (2005) Training, maturation, and genetic influences on the development of executive attention. Proc Natl Acad Sci U S A 102:14931-14936.

Sale A, Maya Vetencourt JF, Medini P, Cenni MC, Baroncelli L, De Pasquale R, Maffei L (2007) Environmental enrichment in adulthood promotes amblyopia recovery through a reduction of intracortical inhibition. Nat Neurosci 10:679-681.

Sato M, Stryker MP 2008. Distinctive features of adult ocular dominance plasticity. J Neurosci 28:10278-10286.

Schmidt RA, Bjork RA (1992) New conceptualizations of practice: common principles in three paradigms suggest new concepts for training. Psychol Sci 3:207-217.

Shatz CJ, Stryker MP (1978) Ocular dominance in layer IV of the cat's visual cortex and the effects of monocular deprivation. J Physiol 281:267-283.

Silingardi D, Scali M, Belluomini G, Pizzorusso T (2010) Epigenetic treatments of adult rats promote recovery from visual acuity deficits induced by long-term monocular deprivation. Eur J Neurosci 31:2185-2192.

Silver MA, Shenhav A, D'Esposito M (2008) Cholinergic enhancement reduces spatial spread of visual responses in human early visual cortex. Neuron 60:904-914.

Southwell DG, Froemke RC, Alvarez-Buylla A, Stryker MP, Gandhi SP (2010) Cortical plasticity induced by inhibitory neuron transplantation. Science 327:1145-1148.

Steriade M (2004) Acetylcholine systems and rhythmic activities during the waking-sleep cycle. Prog Brain Res 145:179-196.

Stern EA, Maravall M, Svoboda K (2001) Rapid development and plasticity of layer 2/3 maps in rat barrel cortex in vivo. Neuron 31:305-315.

Stevens B, Allen NJ, Vazquez LE, Howell GR, Christopherson KS, Nouri N, Micheva KD, Mehalow AK, Huberman AD, Stafford B, Sher A, Litke AM, Lambris JD, Smith SJ, John SW, Barres BA (2007) The classical complement cascade mediates CNS synapse elimination. Cell 131:1164-1178.

Stimson L, Wood V, Khan O, Fotheringham S, La Thangue NB (2009) HDAC inhibitor-based therapies and haematological malignancy. Ann Oncol 20:1293-1302.

Sugiyama S, Di Nardo AA, Aizawa S, Matsuo I, Volovitch M, Prochiantz A, Hensch TK (2008) Experience-dependent transfer of Otx2 homeoprotein into the visual cortex activates postnatal plasticity. Cell 134:508-520.

Syken J, Grandpre T, Kanold PO, Shatz CJ (2006) PirB restricts oculardominance plasticity in visual cortex. Science 313:1795-1800. 
Tang YY, Ma Y, Wang J, Fan Y, Feng S, Lu Q, Yu Q, Sui D, Rothbart MK, Fan M, Posner MI (2007) Short-term meditation training improves attention and self-regulation. Proc Natl Acad Sci U S A 104:1715217156.

Thomas BP, Welch EB, Niederhauser BD, Whetsell WO Jr, Anderson AW, Gore JC, Avison MJ, Creasy JL (2008) High-resolution 7T MRI of the human hippocampus in vivo. J Magn Reson Imaging 28:1266-1272.

Thompson B, Mansouri B, Koski L, Hess RF (2008) Brain plasticity in the adult: modulation of function in amblyopia with rTMS. Curr Biol 18:1067-1071.

Trachtenberg JT, Trepel C, Stryker MP (2000) Rapid extragranular plasticity in the absence of thalamocortical plasticity in the developing primary visual cortex. Science 287:2029-2032.

Vereecken EP, Brabant P (1984) Prognosis for vision in amblyopia after loss of the good eye. Arch Ophthalmol 102:220-224.

Vygotsky LS 1978 Mind and society: the development of higher psychological processes. Cambridge, MA: Harvard UP.
Wandell BA, Smirnakis SM (2009) Plasticity and stability of visual field maps in adult primary visual cortex. Nat Rev Neurosci 10:873-884.

Wang BS, Sarnaik R, Cang J (2010) Critical period plasticity matches binocular orientation preference in the visual cortex. Neuron 65: 246-256.

Weinberger NM (2007) Auditory associative memory and representational plasticity in the primary auditory cortex. Hearing Res 229:54-68.

Xiang Z, Huguenard JR, Prince DA (1998) Cholinergic switching within neocortical inhibitory networks. Science 281:985-988.

Yang T, Maunsell JH (2004) The effect of perceptual learning on neuronal responses in monkey visual area V4. J Neurosci 24:1617-1626.

Yazaki-Sugiyama Y, Kang S, Câteau H, Fukai T, Hensch TK (2009) Bidirectional plasticity in fast-spiking GABA circuits by visual experience. Nature 462:218-221.

Zhang TY, Meaney MJ (2010) Epigenetics and the environmental regulation of the genome and its function. Annu Rev Psychol 61:439-466. 